\title{
Efficient secretion of the model antigen M6-gp41E in Lactobacillus plantarum NCIMB 8826
}

\author{
Pascal Hols, ${ }^{1}$ Philippe Slos, ${ }^{2}$ Philippe Dutot, ${ }^{2}$ Jacqueline Reymund, ${ }^{2}$ \\ Paul Chabot, ${ }^{2}$ Brigitte Delplace, ${ }^{1}$ Jean Delcour ${ }^{1}$ and Annick Mercenier ${ }^{2} \dagger$
}

Author for correspondence: Jean Delcour. Tel: +3210 473484. Fax: +3210473109. e-mail: delcour@gene.ucl.ac.be

1 Unité de Génétique, Université catholique de Louvain, 5 Place Croix du Sud, B-1348 Louvain-laNeuve, Belgium

2 Transgène SA, 11 rue de Molsheim, F-67082

Strasbourg Cedex, France

\begin{abstract}
Four Lactobacillus strains (Lb. plantarum NCIMB 8826, Lb. paracasei LbTGS1.4, Lb. casei ATCC 393 and $L b$. fermentum KLD) were tested for their ability to produce and secrete heterologous proteins. These strains were first screened with an $\alpha$-amylase reporter under the control of a set of expression or expression/secretion signals from various lactic acid bacteria. With most of the constructions tested, the level of extracellular production was highest in $\mathbf{L b}$. plantarum NCIMB 8826, and lowest in Lb. paracasei LbTGS1.4. These two strains were next assayed using a model antigen consisting of the $\mathbf{N}$-terminal part of the M6 protein from Streptococcus pyogenes fused to the linear epitope ELDKWAS from human immunodeficiency virus gp41 protein. Secretion of this heterologous protein was inefficient in $\mathbf{L b}$. paracasei LbTGS1.4, which accumulated a large intracellular pool of the unprocessed precursor, whereas Lb. plantarum NCIMB 8826 was able to secrete the antigen to a level as high as $10 \mathrm{mg} \mathrm{I}^{-1}$.
\end{abstract}

Keywords: Lactobacillus, secretion, $\alpha$-amylase, M6 protein, mucosal vaccines

\section{INTRODUCTION}

Lactobacilli are used in various processes such as dairy fermentation, baking, production of alcoholic beverages, sausage and meat preservation, pickling of vegetables and silage making. Some members of the genus are commensal colonizers of mammalian gastrointestinal systems and this colonization is thought to have beneficial effects on health and nutrition (Chassy, 1987; Fernandes et al., 1987; Marteau \& Rambaud, 1993; Pouwels \& Leer, 1993).

Recently, lactobacilli have been considered as potential antigen delivery vehicles for the development of mucosal vaccines since they display a number of advantages. Lactobacilli are GRAS (generally recognized as safe) micro-organisms. Furthermore, lactobacilli are able to cross the digestive tract and some of them are maintained transiently or for a longer term as a stable population in the gut (Link-Amster et al., 1994; Marteau

\footnotetext{
†Present address: Service de Microbiologie des Ecosystèmes, Institut Pasteur de Lille, 1 rue du Professeur Calmette BP 245, F-59019 Lille Cedex, France.
}

Abbreviations: gp41E, epitope from the human immunodeficiency virus gp41 protein; LAB, lactic acid bacteria; TIR, translation initiation region.
\& Rambaud, 1993). Finally, they possess intrinsic adjuvancy and low immunogenicity (Pouwels et al., 1996; Perdigon et al., 1988). Lactobacilli are also an alternative to the other GRAS lactic acid bacterium Lactococcus lactis, which has also been evaluated as a live antigen carrier (Norton et al., 1994; Wells et al., 1993a), the main difference being the capacity of some lactobacilli to colonize the gut mucosa while no implantation can be detected for Lc. lactis (Klijn et al., 1995).

An important consideration in the development of a live mucosal vaccine concerns the location of the antigen (intracellular, extracellular or cell-wall anchored). With live enteric vectors such as Salmonella typhimurium or Escherichia coli, cell surface presentation has been considered advantageous for efficiently inducing an antibody response (Leclerc et al., 1991; Schorr et al., 1991). Cell surface exposure of antigens or epitopes in Gram-positive bacteria has only recently been investigated. An anchoring system for the mouth commensal bacterium Streptococcus gordonii has been developed on the basis of the fibrillar M6 protein (Oggioni et al., 1995; Fischetti et al., 1993), whereas anchoring in the non-pathogenic bacteria Staphylococcus xylosus and Staphylococcus carnosus is based on protein A from 
Staphylococcus aureus (Samuelson et al., 1995; Nguyen et al., 1993). Like nearly all surface molecules from Gram-positive bacteria, these two proteins follow the general secretion pathway for their external location, and anchoring per se takes place in a second step owing to the presence of an anchoring hydrophobic C-terminal domain associated with a conserved motif, LPXTGX (Schneewind et al., 1995; Fischetti et al., 1993).

The general context of this work deals with the implementation of the M6 epitope carrier system in lactobacilli and more precisely concerns the evaluation of the secretion capacity of different Lactobacillus strains, since secretion is a prerequisite of the anchoring process. Secretion efficiency is clearly a limitation factor for the extracellular production of heterologous proteins in a number of lactic acid bacteria (LAB), which, for this reason, are generally considered as poor secretors (Mercenier et al., 1994; Wells et al., 1993b). We have investigated the extracellular production of $\alpha$-amylase used as reporter in four different strains of lactobacilli. In a second step, we analysed the capacity of two of these strains to secrete a model antigen comprising the $\mathrm{N}$-terminal part of the M6 protein fused to an epitope derived from the human immunodeficiency virus (HIV) gp41 protein (M6-gp41E).

\section{METHODS}

Plasmids, bacterial strains and culture conditions. The plasmids and bacterial strains used in this study are listed in Table 1. Plasmids used in lactobacilli all replicated as rolling circles. E. coli was grown in Luria-Bertani medium. E. coli MC1061 was used as host strain for the propagation of plasmids pTG2247, pTG2257, pTG2281 and pTG3237; the other plasmids were prepared from E. coli TG1. All Lactobacillus strains were routinely grown in MRS medium (Difco). Amylase activity was detected on plates by incorporating $0.2 \%(\mathrm{w} / \mathrm{v})$ starch in MRS medium containing $0 \cdot 2 \%(\mathrm{w} / \mathrm{v})$ glucose instead of $2 \%(\mathrm{w} / \mathrm{v})$ and subsequently visualizing starch degradation haloes by staining with iodine vapours (Merck). Antibiotics were used at the following concentrations: $20 \mu \mathrm{g}$ chloramphenicol $\mathrm{ml}^{-1}$ and $10 \mu \mathrm{g}$ chloramphenicol plus $12.5 \mu \mathrm{g}$ streptomycin $\mathrm{ml}^{-1}$ for E. coli; $10 \mu \mathrm{g}$ chloramphenicol $\mathrm{ml}^{-1}$ for Lactobacillus plantarum NCIMB $8826 ; 7.5 \mu \mathrm{g}$ chloramphenicol $\mathrm{ml}^{-1}$ for Lactobacillus paracasei LbTGS1.4, Lactobacillus fermentum KLD and Lactobacillus casei ATCC 393.

DNA manipulations and transformation. All DNA manipulations were carried out as described previously (Hols et al., 1992, 1994). Plasmid DNA from $L b$. plantarum was isolated as described by Posno et al. (1991). Plasmid DNA from $L b$. paracase $i$ LbTGS1.4 and Lb. case i ATCC 393 was isolated as described by O'Sullivan \& Klaenhammer (1993). Preparation of plasmid DNA from $L b$. fermentum was performed by the same procedure except that cells from a $2 \mathrm{ml}$ overnight culture were harvested by centrifugation $\left(13000 \mathrm{~g}, 15 \mathrm{~min}, 4^{\circ} \mathrm{C}\right)$, resuspended in $400 \mu \mathrm{l} 25 \%(\mathrm{w} / \mathrm{v})$ sucrose containing $50 \mathrm{mg}$ lysozyme $\mathrm{ml}^{-1}$ and further incubated at $37^{\circ} \mathrm{C}$ for $1 \mathrm{~h}$. Electroporation of $\mathrm{Lb}$. plantarum NCIMB 8826 was performed as described by Josson et al. (1989). Electroporation of Lb. paracasei LbTGS1.4 and Lb. casei ATCC 393 was conducted as follows. An overnight culture was diluted 100fold in $300 \mathrm{ml}$ MRS medium supplemented with $20 \mathrm{mM} \mathrm{D} / \mathrm{L}-$ threonine. Cells were harvested by centrifugation $(12000 \mathrm{~g}$, $10 \mathrm{~min}, 4^{\circ} \mathrm{C}$ ) at an $\mathrm{OD}_{600}$ of $0 \cdot 1$. The pellet was washed three times with ice-cold electroporation buffer $(272 \mathrm{mM}$ sucrose, $1 \mathrm{mM}$ HEPES, $\mathrm{pH} \mathrm{6.5)}$ and finally resuspended in $3 \mathrm{ml}$ of the same buffer. The cell suspension $(80 \mu \mathrm{l})$ was mixed with $100 \mathrm{ng}$ plasmid DNA and transferred into an electroporation cuvette $(0 \cdot 2 \mathrm{~cm})$. A single pulse of $11 \mathrm{kV}$ was applied with a capacitance of $25 \mu \mathrm{F}$ and a resistance of $200 \Omega$ (Bio-Rad apparatus). After electroporation, cells were directly diluted with $300 \mu \mathrm{l} \mathrm{MRS}$ and incubated for $2 \mathrm{~h}$ at $37^{\circ} \mathrm{C}$. Transformants were visible after $48 \mathrm{~h}$ incubation at $37^{\circ} \mathrm{C}$ under aerobic conditions. Electroporation of $\mathrm{Lb}$. fermentum KLD was performed according to the previous protocol with the following modifications: the overnight culture was diluted 100 -fold in $50 \mathrm{ml}$ MRS medium without threonine, cells were harvested at an $\mathrm{OD}_{600}$ of $0 \cdot 2$, the electroporation buffer was adjusted to $\mathrm{pH} 6.0$ and the cells were resuspended in $1 \mathrm{ml}$ of the same buffer after the washing steps. After electroporation, cells were directly diluted with $1 \mathrm{ml}$ MRS and incubated for $2 \mathrm{~h}$ at $37^{\circ} \mathrm{C}$. Plates were incubated under anaerobic conditions (Gaspak System; BRL).

$\alpha$-Amylase assay. Cell culture and fractionation and the $\alpha$ amylase activity test (Phedebas kit; Pharmacia) were performed as described previously (Hols et al., 1994). Total protein in cell extracts was measured with Bio-Rad protein assay reagent on the basis of the Bradford (1976) staining procedure.

Western blotting and ELISA assay. Protein extracts and culture supernatants were prepared from MRS cultures grown for $9 \mathrm{~h}$ at $37^{\circ} \mathrm{C}$. Total protein extracts were prepared by sonication (Sonifier 450; Branson Ultrasonics); clear lysates were usually obtained after $12-16 \times 30 \mathrm{~s}$. Culture supernatants from $L b$. plantarum NCIMB 8826 were directly mixed with Laemmli sample buffer, whereas those from $L b$. paracase $i$ LbTGS1.4 were filtered through $0.22 \mu \mathrm{m}$ Millex HA (Millipore) membranes and precipitated with $10 \%(\mathrm{w} / \mathrm{v})$ icecold TCA. After centrifugation, the pellets were washed once with ice-cold ethanol and resuspended in Laemmli sample buffer (Laemmli, 1970). Protein extracts and culture supernatants were separated by SDS-PAGE (Laemmli, 1970) and electrophoretically blotted onto nitrocellulose sheets as described by Towbin et al. (1979). The subsequent steps were carried out as specified by the suppliers of the Western blot AP system (Protoblot; Promega). Immunoblots were performed with anti-gp41E antibodies (human monoclonal 2F5; 1/7500 dilution) as primary antibodies (Dutot, 1996). Rainbow markers (Amersham) were used as standards. The ELISA assay was based on the end-point method. Anti-gp41E antibodies (1/7500 dilution) and biotinylated anti-mouse antibodies (1/500 dilution; Amersham) were used as primary and secondary antibodies, respectively. After the addition of the streptavidin/peroxidase complex $(1 / 1000$ dilution; Amersham), staining was obtained by incubation with $o$ phenylenediamine (Sigma) plus hydrogen peroxide. Plate readings were made with a Vmax machine (Molecular Devices) at $490 \mathrm{~nm}$.

\section{RESULTS}

\section{Screening of Lactobacillus strains for extracellular production using $\alpha$-amylase as reporter}

A first step towards the development of oral vaccines based upon recombinant live lactobacilli was to evaluate the ability of various commensal species to efficiently secrete a model foreign protein. We first selected $L b$. 
Table 1. Plasmids and bacterial strains

\begin{tabular}{|c|c|c|}
\hline Plasmid or strain & Relevant features & Reference/source \\
\hline \multicolumn{3}{|l|}{ Plasmids } \\
\hline pTG290 & $\begin{array}{l}\text { Lc. lactis } \mathrm{pSH} 71 \text { replicon; pCK17 derivative carrying the } \\
\text { amyL gene under the control of the P25 promoter from } S \text {. } \\
\text { thermophilus; } \mathrm{Km}^{\mathrm{r}} \mathrm{Cm}^{\mathrm{r}}\end{array}$ & Slos $(1990)$ \\
\hline pGIT008 & $\begin{array}{l}\text { Lc. lactis } \mathrm{pSH} 71 \text { replicon; pGIP331 derivative carrying the } \\
\text { amyL gene under the control of a strong } L b \text {. plantarum } \\
\text { promoter; } \mathrm{Km}^{\mathrm{r}} \mathrm{Cm}^{\mathrm{r}} \mathrm{Str}^{\mathrm{r}}\end{array}$ & Hols et al. (1994) \\
\hline pGIP312.4 & $\begin{array}{l}\text { Lc. lactis } \mathrm{pSH} 71 \text { replicon; pGIP312 derivative carrying the } \\
\text { amyL gene under the control of an expression/secretion } \\
\text { cassette isolated from Ent. faecalis; } \mathrm{Km}^{\mathrm{r}} \mathrm{Cm}^{\mathrm{r}} \mathrm{Str}^{\mathrm{r}}\end{array}$ & Hols et al. (1994) \\
\hline pGIP212.4 & Lc. lactis $\mathrm{pW} 01$ replicon; pGIP212 derivative carrying the & Hols et al. (1994) \\
\hline pGIP212.12 & $\begin{array}{l}\text { amyL gene under the control of an expression/secretion } \\
\text { cassette from Ent. faecalis; } \mathrm{Em}^{\mathrm{r}} \mathrm{Cm}^{\mathrm{r}} \mathrm{Str}^{\mathrm{r}}\end{array}$ & \\
\hline pGIP212.7 and & $\begin{array}{l}\text { Lc. lactis } \mathrm{pW} 01 \text { replicons; pGIP212 derivatives with the amyL } \\
\text { under the control of two different expression/secretion } \\
\text { cassettes isolated from } L b \text {. plantarum; } \mathrm{Em}^{\mathrm{r}} \mathrm{Cm}^{\mathrm{r}} \mathrm{Str}^{\mathrm{r}}\end{array}$ & Hols et al. (1994) \\
\hline $\mathrm{pNZ} 10 \alpha 1$ & $\begin{array}{l}\text { Lc. lactis } \mathrm{pSH} 71 \text { replicon; } \mathrm{pNZ} 123 \text { derivative carrying the } \\
\text { amyS gene under the control of } L c \text {. lactis usp } 45 \\
\text { expression/secretion signals; } \mathrm{Cm}^{\mathrm{r}}\end{array}$ & Van Asseldonk (1993) \\
\hline pTG2257 & pGP603 derivative carrying the M6-gp41E fusion protein & P. Slos (unpublished) \\
\hline pTG2247 & $\begin{array}{l}\text { Lc. lactis pSH71 replicon; pCK17 derivative; expression } \\
\text { vector containing the } \mathrm{P} 25 \text { promoter from } S \text {. thermophilus } \\
\text { followed by the } l d b D \mathrm{RBS} \text { from } L b \text {. pentosus; } \mathrm{Km}^{\mathrm{r}} \mathrm{Cm}^{\mathrm{r}}\end{array}$ & P. Slos (unpublished) \\
\hline pTG2281 & $\begin{array}{l}\text { pTG2247 derivative containing an ATG translation fusion } \\
\text { between pre-M6-gp41E and the pTG2247 expression signals; } \\
\mathrm{Km}^{\mathrm{r}} \mathrm{Cm}^{\mathrm{r}}\end{array}$ & This study \\
\hline pTG3237 & pTG2281 derivative with a modified TIR; $\mathrm{Km}^{\mathrm{r}} \mathrm{Cm}^{\mathrm{r}}$ & This study \\
\hline pGK13 & Shuttle vector for E. coli and Lc. lactis; $\mathrm{Em}^{\mathrm{r}} \mathrm{Cm}^{\mathrm{r}}$ & Kok et al. (1984) \\
\hline \multicolumn{3}{|l|}{ Strains } \\
\hline E. coli MC1061 & araD139 $\Delta($ ara-leu $) 7696$ lacX74 galV galK hsr-bsm rpsL & Casadaban \& Cohen $(1980)$ \\
\hline E. coli TG1 & $\begin{array}{l}\mathrm{K}-12 \Delta\left(\text { lac-pro) supE thi hsd5 } \mathrm{F}^{\prime} \text { traD36 proA } A^{+} B^{+} \text {lacl }\right. \\
\text { lacZ } \mathrm{M} 5\end{array}$ & Sambrook et al. (1989) \\
\hline Lb. casei ATCC 393 & Isolated from cheese & $\begin{array}{l}\text { American Type Culture } \\
\text { Collection, Rockville, MD, } \\
\text { USA }\end{array}$ \\
\hline Lb. fermentum KLD & Isolated from human faeces & Gibson \& Conway (1992) \\
\hline $\begin{array}{l}\text { Lb. paracasei } \\
\text { LbTGS1.4 }\end{array}$ & Isolated from murine vagina & Transgène SA \\
\hline $\begin{array}{l}\text { Lb. plantarum } \\
\text { NCIMB } 8826\end{array}$ & Isolated from human saliva & $\begin{array}{l}\text { National Collections of } \\
\text { Industrial and Marine } \\
\text { Bacteria, Aberdeen, UK }\end{array}$ \\
\hline
\end{tabular}

paracasei LbTGS1.4, a murine isolate of vaginal origin able to colonize the gastro-intestinal and vaginal tracts of the mouse for about 1 and 3 weeks, respectively (Dutot, 1996); this strain was of interest since the mouse was chosen first as an experimental system. We also tested three additional strains: Lb. fermentum KLD from human faeces, $L b$. plantarum NCIMB 8826 from human saliva and Lb. casei ATCC 393 from cheese.

A range of $\alpha$-amylase constructs was tested in these different hosts. An $\alpha$-amylase reporter (amyL from Bacillus licheniformis or amyS from Bacillus stearothermophilus) was brought under the control of different expression or expression/secretion signals originating from different LAB such as Lb. plantarum (pGIT008, pGIP212.7, pGIP212.12), Lc. lactis (pNZ10 1 1), Streptococcus thermophilus (pTG290) and Enterococcus faecalis (pGIP212.4, pGIP312.4) (Table 1). The genetic fusions were simple transcriptional fusions in pTG290 and pGIT008 or translational fusions between expression/secretion signals and the $\alpha$-amylase reporter in all the other constructs tested.

Seven $\alpha$-amylase constructs were transferred by electroporation into $L b$. plantarum NCIMB 8826 and $L b$. paracasei LbTGS1.4. The $\alpha$-amylase phenotype was 

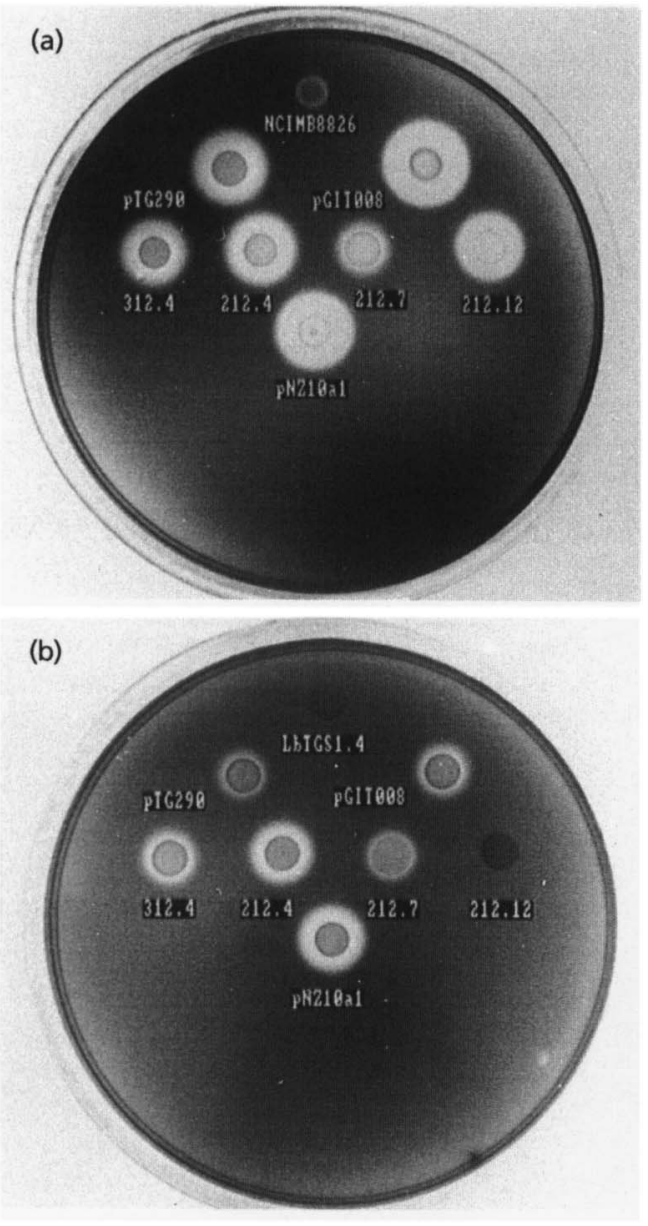

Fig. 1. lodine plate test for $\alpha$-amylase activities of two Lactobacillus strains transformed with various plasmids on MRS medium supplemented with $0.2 \%(\mathrm{w} / \mathrm{v})$ glucose and $0.2 \%(\mathrm{w} / \mathrm{v})$ soluble starch. (a) Lb. plantarum NCIMB 8826; (b) Lb. paracasei LbTGS1.4. Wild-type strains are labelled NCIMB 8826 and LbTGS1.4, and recombinant strains are named according to the serial number of the harboured plasmid. Haloes of starch degradation were visualized after $16 \mathrm{~h}$ growth by staining the plates with iodine vapours. tested on MRS plates containing $0 \cdot 2 \%(\mathrm{w} / \mathrm{v})$ glucose and $0.2 \%(\mathrm{w} / \mathrm{v})$ starch (Fig. 1). All the recombinant strains displayed a positive phenotype in NCIMB 8826 and LbTGS1.4 with the exception of pGIP212.12 in LbTGS1.4. A visual comparison of the halo in NCIMB 8826 and LbTGS1.4 recombinant strains clearly showed that all the NCIMB 8826 recombinant strains displayed a larger halo size (Fig. 1). Fractionation experiments performed on these recombinant strains demonstrated that the $\alpha$-amylase specific activity was generally higher in the supernatant of strain NCIMB 8826 (Table 2), confirming the observations made on the haloes. In most recombinant strains, $\alpha$-amylase activity was mainly located in the supernatant, with the exception of pNZ10 $\alpha 1$, where approximately $50 \%$ of the amylase activity was associated with the cell pellet (Table 2).

In addition to the transfer of a range of $\alpha$-amylase constructs in $L b$. plantarum NCIMB 8826 and $L b$. paracasei LbTGS1.4, some constructions were also tested in Lb. fermentum KLD and Lb. casei ATCC 393. The transfer of plasmids pTG290, pGIP008 and pGIP312.4 was unsuccessful in Lb. fermentum, even after repeated trials. Plasmids pGIP212.4 and pNZ10 $\alpha 1$ were successfully transferred in that strain but a majority of the primary transformants were $\alpha$-amylase-negative, suggesting an early structural instability of these plasmids. This was confirmed for plasmid pNZ10 $\alpha 1$, where a region of $1.2 \mathrm{~kb}$ was systematically deleted (data not shown). Four of these $\alpha$-amylase constructs were successfully introduced and stably maintained in $L b$. casei ATCC 393, and the results were similar to those obtained in Lb. paracasei LbTGS1.4 (Table 2).

\section{Construction of M6-gp41E expression/secretion plasmids}

To assess whether the observed differences in extracellular production would hold true for another protein, secretion of a model antigen (M6-gp41E) was evaluated in the two most divergent strains, $L b$. plantarum NCIMB 8826 (high $\alpha$-amylase production) and $L b$.

Table 2. $\alpha$-Amylase activity in culture supernatants and cell extracts of different recombinant Lactobacillus strains

Activity is expressed as $10^{-2} \times \alpha$-amylase units (mg total protein $)^{-1}$, mean of two experiments. ND, Plasmid not transferred. - , Unsuccessful transfer or structural instability of the plasmid.

\begin{tabular}{|c|c|c|c|c|c|c|c|c|}
\hline \multirow[t]{2}{*}{ Plasmid } & \multicolumn{2}{|c|}{ Lb. plantarum NCIMB 8826} & \multicolumn{2}{|c|}{ Lb. paracasei LbTGS1.4 } & \multicolumn{2}{|c|}{ Lb. casei ATCC 393} & \multicolumn{2}{|c|}{ Lb. fermentum KLD } \\
\hline & Supernatant & Cell extract & Supernatant & Cell extract & Supernatant & Cell extract & Supernatant & Cell extract \\
\hline pTG290 & 52 & $<1$ & 12 & $<1$ & 7 & $<1$ & - & - \\
\hline pGIT008 & 148 & 12 & 7 & $<1$ & 20 & $<1$ & - & - \\
\hline pGIP312.4 & 87 & $11 \cdot 5$ & 2 & $<1$ & 7 & $<1$ & - & - \\
\hline pGIP212.4 & 83 & 24 & 48 & $1 \cdot 5$ & - & - & 54 & 20 \\
\hline pGIP212.7 & 18 & $<1$ & 2 & $<1$ & ND & ND & ND & ND \\
\hline pGIP212.12 & 38 & 22 & $<1$ & $<1$ & ND & ND & ND & ND \\
\hline $\mathrm{pNZ10} \alpha 1$ & 102 & 135 & 142 & 119 & 125 & 190 & 22 & 59 \\
\hline
\end{tabular}




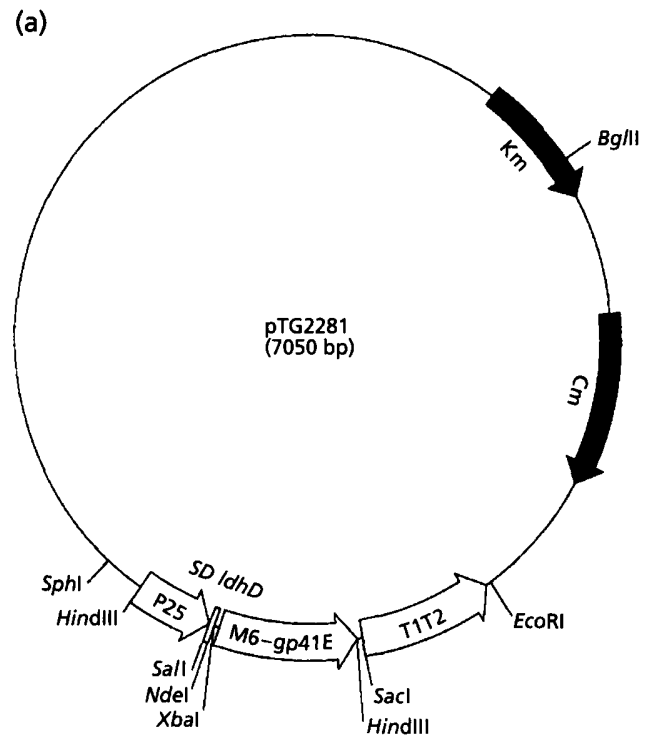

(b)

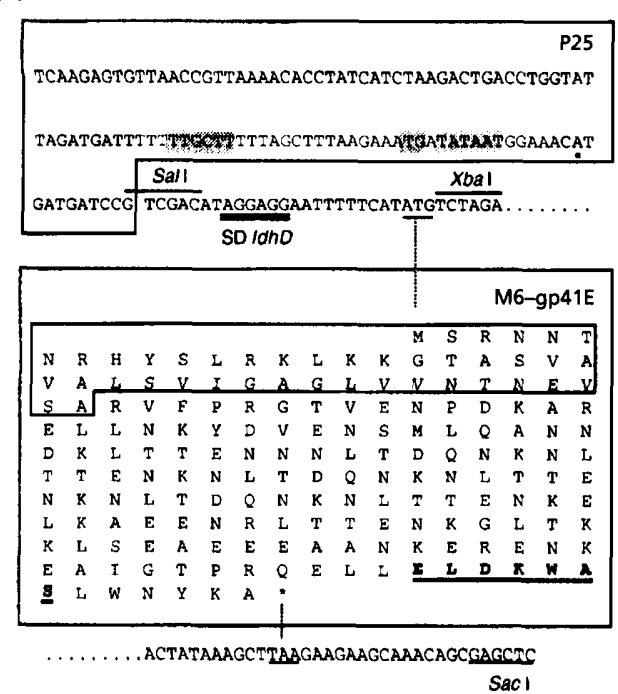

(c)

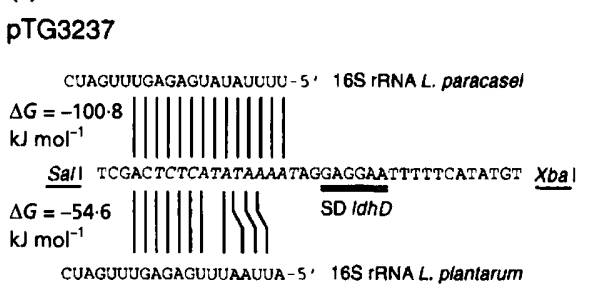

Fig. 2. Structure of the pTG2281 and pTG3237 plasmids. (a) Partial restriction map of pTG2281. P25, S. thermophilus P25 promoter (Slos et al., 1991); SD /dhD, Shine-Dalgarno sequence from the $L b$. pentosus IdhD gene (Taguchi \& Ohta, 1991); M6-gp41E, translation fusion between the N-terminal part of M6 protein and a linear epitope from HIV gp41 protein; T1T2, $E$. coli transcriptional terminators; $\mathrm{Km}$, kanamycin resistance gene; $\mathrm{Cm}$, chloramphenicol resistance gene. (b) Organization of the region between HindIII and SaCl in pTG2281. The upper box corresponds to promoter P25. The transcriptional start mapped in $S$. thermophilus (.) and the putative -35 and -10 boxes (shaded) are indicated. The Safl and $X b a l$ sites used to construct pTG3237 are overlined. The Shine-Dalgarno sequence is double paracasei LbTGS1.4 (low $\alpha$-amylase production). This antigen is a fusion between the first $122 \mathrm{~N}$-terminal amino acids of the mature form of M6 protein (Fischetti et al., 1993; Hollingshead et al., 1986) and the linear Bcell epitope ELDKWAS of protein gp41 from HIV (Muster et al., 1994) (Fig. 2b).

The precursor protein (pre-M6-gp41E) was PCRamplified from plasmid pTG2257 using the following oligonucleotides: OTG5508 (5'-AATGTCTAGAAATAACACGAATAGACACTAT- $\left.3^{\prime}\right)$, which included a $\mathrm{XbaI}$ site (underlined), and OTG5592 (3'-CGAATTCTTCTTCGTTTGTCGCTCGAGCGAC-5'), which included a SacI site (underlined). The 572 bp DNA fragment of the PCR reaction was cleaved by $X b a \mathrm{I}$ and SacI and inserted in the corresponding site of the expression vector $\mathrm{pTG} 2247$ (Table 1). A restriction map of the resulting pTG2281 plasmid and the organization of the fusion are presented in Fig. 2(a) and Fig. 2(b), respectively. We used the $\mathrm{P} 25$ promoter from $S$. thermophilus (Slos et al., 1991) and the Shine-Dalgarno sequence from the Lactobacillus pentosus ldhD gene (Taguchi \& Ohta, 1991) to drive expression of the preM6-gp41E protein. To direct secretion through the general secretion pathway, we took the genuine 42 amino acid M6 signal sequence (Hollingshead et al., 1986) except that amino acids 2 and 3 (Ala and Lys) were changed into Ser and Arg as a result of using the $\mathrm{XbaI}$ site in the ATG fusion. This modification was expected to have a negligible effect on the function of the $\mathrm{N}$ terminal part of the signal sequence since the number of positively charged amino acids remained unchanged in the ' $n$ ' region of the signal sequence (Simonen \& Palva, 1993).

A number of $L b$. plantarum translation initiation regions (TIRs) have been reported to contain additional motifs ( $5^{\prime}$-boxes) besides the Shine-Dalgarno sequences that could interact with the $5^{\prime}$-end of the $16 \mathrm{~S}$ rRNA (Hols et al., 1994). Therefore, in an attempt to improve translation, a modified version of plasmid pTG2281 was constructed by inserting a $5^{\prime}$-box in front of the $l d h D$ Shine-Dalgarno sequence. A synthetic linker composed of the complementary oligonucleotides OTG5930 (5'TCGACTCTCATATAAAATAGGAGGAATTTTT CATATGT-3') and OTG5931 (5'-CTAGACATATGAAAAATTCCTCCTATTTTATATGAGAG-3') (compatible $X b a I$ and SalI termini underlined) was inserted between the same sites in pTG2281. The resulting plasmid, pTG3237, contains in front of the ldhD Shine-Dalgarno sequence 14 nucleotides comple-

underlined. The start (ATG) and stop (TAA) codons of the M6-gp41E ORF are underlined. The lower box corresponds to the fusion protein M6-gp41E; the enclosed box delineates the signal sequence. The C-terminal epitope gp41E (bold) is underlined. (c) DNA sequence between Sall and $X$ bal in pTG3237; putative interactions with the 5 -ends of the $16 \mathrm{~S}$ rRNA of $L b$. paracasei $\left[\Delta G=-24.0 \mathrm{kcal} \mathrm{mol}^{-1}(-100.8 \mathrm{~kJ}\right.$ $\left.\left.\mathrm{mol}^{-1}\right)\right]$ and $L b$. plantarum $\left[\Delta G=-13.0 \mathrm{kcal} \mathrm{mol}^{-1}(-54.6 \mathrm{~kJ}\right.$ $\left.\mathrm{mol}^{-1}\right)$ ] are presented (Tinoco et al., 1973). The Shine-Dalgarno sequence is double underlined. 


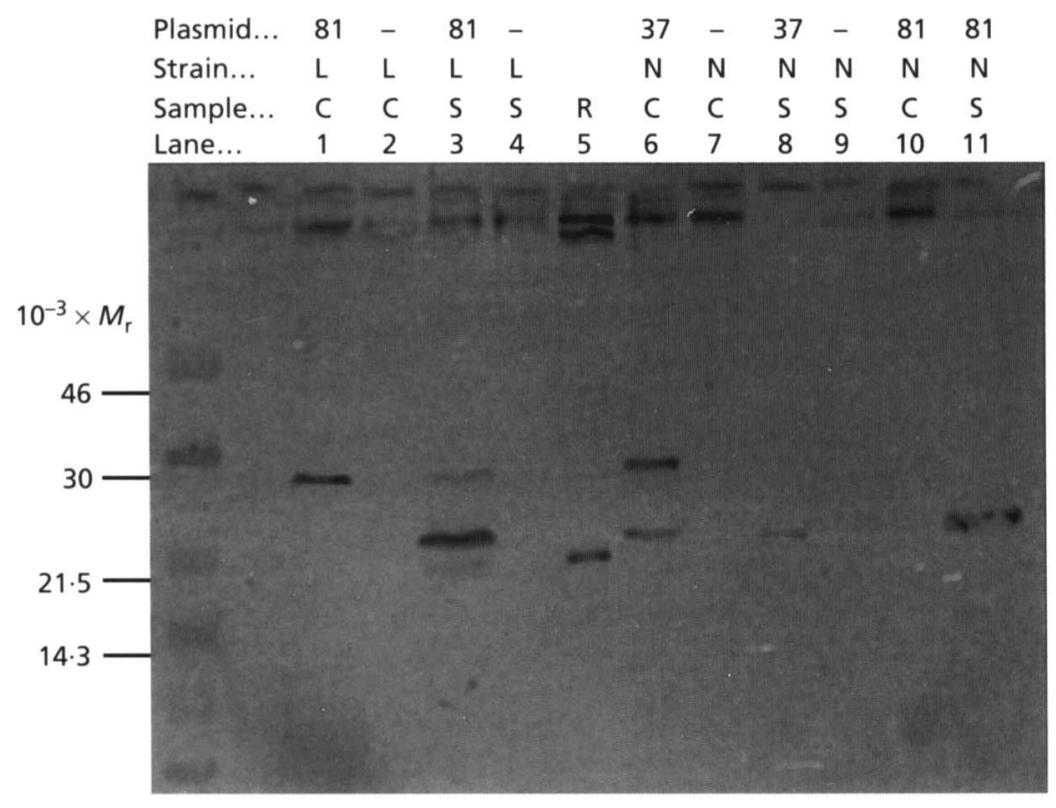

Fig. 3. Western blot analysis of recombinant NCIMB 8826 and LbTGS1.4 clones with an anti-gp41E monoclonal antibody. Plasmids: 37, pTG3237; 81, pTG2281; - , pTG2247 or pGK13 used as negative controls. Strains: $L$, Lb. paracasei LbTGS1.4; N, Lb. plantarum NCIMB 8826. Samples: $C$, cell extract; $S$, supernatant; $R$, purified M6-gp41E. Lanes: 1 , total cell extract from LbTGS1.4 harbouring pTG2281 ( $30 \mu \mathrm{g}$ total protein); 2 , total cell extract from LbTGS1.4 harbouring pTG2247 (20 $\mu \mathrm{g}$ total protein); 3 , supernatant ( $1 \mathrm{ml}$ TCA-precipitated) from LbTGS1.4 harbouring pTG2281: 4, supernatant (1 $\mathrm{ml}$ TCA-precipitated) from LbTGS1.4 harbouring PTG2247; 5, purified M6-gp41E; 6 , total cell extract from NCIMB 8826 harbouring pTG3237 $(20 \mu \mathrm{g}$ total protein): 7, total cell extract from NCIMB 8826 harbouring pGK13 $(20 \mu \mathrm{g}$ total protein); 8 , supernatant $(2 \mu \mathrm{l})$ from NCIMB 8826 harbouring PTG3237; 9, supernatant $(20 \mu \mathrm{l})$ from NCIMB 8826 harbouring pGK13; 10 , total cell extract from NCIMB 8826 harbouring pTG2281 ( $30 \mu \mathrm{g}$ total protein); 11 , supernatant $(24 \mu \mathrm{l})$ from NCIMB 8826 harbouring pTG2281.

mentary to the $5^{\prime}$-end of the $16 \mathrm{~S} \mathrm{rRNA}$ of $L b$. case $i$ $\left[\Delta G=-24 \mathrm{kcal} \mathrm{mol}^{-1}\left(-100 \cdot 8 \mathrm{~kJ} \mathrm{~mol}^{-1}\right)\right.$; Fig. $\left.2 \mathrm{c}\right]$ and 11 nucleotides complementary to the $5^{\prime}$-end of the $16 \mathrm{~S}$ rRNA of $L b$. plantarum $\left[\Delta G=-13.0 \mathrm{kcal} \mathrm{mol}^{-1}\right.$ $\left(-54.6 \mathrm{~kJ} \mathrm{~mol}^{-1}\right)$; Fig. $\left.2 \mathrm{c}\right]$.

\section{Secretion of M6-gp41E in Lb. plantarum NCIMB 8826 and $L b$. paracasei LbTGS1.4 transformed with plasmid pTG2281}

Plasmid pTG2281 was transferred by electroporation into $L b$. plantarum NCIMB 8826 and $L b$. paracasei LbTGS1.4. A Western blot analysis was performed with cell extracts and supernatant fractions of the two recombinant strains (Fig. 3). The precursor M6-gp41E protein (apparent $M_{\mathrm{r}} 29000$ ) was detected as the main band in the cell extract (Fig. 3, lane 1) and as a minor band in the supernatant (Fig. 3, lane 3) of Lb.paracasei LbTGS1.4(pTG2281). The main band (apparent $M_{\mathrm{r}}$ 23000) detected in $1 \mathrm{ml}$ supernatant from LbTGS1.4(pTG2281) corresponds to the mature protein. This band moved slightly behind the M6-gp41E reference protein (Fig. 3, lane 5), which had been purified from $E$. coli and had a lower $M_{\mathrm{r}}$ than the mature M6-gp41E produced in this work due to modifications of its N-terminus [RVFP to (M) VFP] and C-terminus (LWNYKA to LWN) (P. Slos, unpublished results). The situation was completely different with the recombinant Lb. plantarum NCIMB 8826 strain. The same amount of total cell protein $(30 \mu \mathrm{g})$ as in the case of the LbTGS1.4 recombinant strain was loaded (Fig. 3, lane 10) and no precursor was detected. Furthermore, in only $24 \mu \mathrm{l}$ of unconcentrated supernatant from NCIMB 8826 (pTG2281), we detected a strong band with the same mobility as the major band observed in the TCA precipitate from $1 \mathrm{ml}$ supernatant of LbTGS1.4
(pTG2281) (Fig. 3, lane 11). These observations clearly showed that the pre-M6-gp41E precursor accumulated intracellularly in $L b$. paracasei LbTGS1.4 and only a small fraction of the unprocessed protein was converted into the mature form which could be detected exclusively in the supernatant fraction after strong concentration. Conversely, the precursor protein did not accumulate in Lb. plantarum NCIMB 8826 cells and large amounts of the mature form were detected in the culture supernatant. The amounts of extracellular M6-gp41E proteins were quantified by ELISA essay; $0.2 \mathrm{mg} \mathrm{M6-gp} 41 \mathrm{E}$ $1^{-1}$ was produced by the recombinant LbTGS1.4 strain whereas extracellular production amounted to $1.2 \mathrm{mg}$ $1^{-1}$ in strain NCIMB 8826.

\section{Secretion of M6-gp41E in Lb. plantarum NCIMB 8826 and $L b$. paracasei LbTGS1.4 transformed with pTG3237}

Plasmid pTG3237 was also transferred in $L b$. paracasei LbTGS1.4 and in Lb. plantarum NCIMB 8826. Quantification by ELISA of the extracellular amount of M6-gp41E was performed directly on the supernatants of the two recombinant strains. The amount of the protein produced was low and highly variable among the five different LbTGS1.4 clones studied. However, a 10 -fold increase of extracellular production $(10.4 \mathrm{mg}$ $1^{-1}$ ) was observed for NCIMB 8826 in comparison to the same strain harbouring plasmid pTG2281. Two bands corresponding to the precursor and the mature forms were detected by Western blotting in the cell fraction of NCIMB 8826(pTG3237) (Fig. 3, lane 6), whereas no band was detected in the same amount of cell protein in NCIMB 8826(pTG2281) (Fig. 3, lane 10). In the extracellular fraction, a single band corresponding to the mature form was detected with a loading of only $2 \mu \mathrm{l}$ 
unconcentrated supernatant (Fig. 3, lane 8). Thus, modifying the region in front of the Shine-Dalgarno sequence dramatically boosted the expression level in NCIMB 8826, with the result that a large increase in extracellular production of M6-gp41E was achieved, together with the retention of small amounts of the precursor and the mature forms inside the cell.

\section{DISCUSSION}

The main goal of this study was to investigate the secretion capacity of a few strains of lactobacilli for their future use as a live antigen carrier in the development of mucosal vaccines. These strains were initially selected on the basis of different criteria such as genetic amenability (e.g. transformation), human or dairy origin and their capacity to colonize the gastro-intestinal tract of the mouse used as a model system.

The first part of this work was an evaluation of the capacity of four selected strains to deliver an $\alpha$-amylase reporter extracellularly under the control of a set of expression or expression/secretion signals from different LAB. This reporter was chosen since it has already been used with success for secretion studies in a number of LAB (Hols et al., 1992, 1994; Perez-Martinez et al., 1992; Van Asseldonk et al., 1993). This preliminary screening made clear that $L b$. plantarum NCIMB 8826 displayed the highest level of amylase activity in the extracellular medium for the majority of the amylase constructs tested. $L b$. paracase $i$ LbTGS1.4 and $L b$. casei ATCC 393 were much less efficient in this respect and $L b$. fermentum KLD was excluded from further investigations as a majority of the plasmids tested in this strain were structurally unstable. Variation observed in the level of extracellular amylase production could of course result from differences in the level of transcription and/or translation, in mRNA stability or in the copy number of the plasmids. However, a range of expression/secretion signals from various LAB were assayed in this screening which all led to better amylase production in $\mathrm{Lb}$. plantarum NCIMB 8826. Previously, Lb. plantarum NCIMB 8826 had already been shown to be an efficient secretor in comparison to other $L b$. plantarum strains (Fitzsimons et al., 1994; Hols et al., 1994). Therefore, we believe that the low level of extracellular amylase production in strains LbTGS1.4 and ATCC 393 results from low efficiency of the secretion process. However, fractionation experiments did not confirm the expectation that a high amylase activity would be found in the intracellular fraction of the two strains except when plasmid pNZ10 $\alpha 1$ was used, but in this case high intracellular amylase activity was observed in all the different hosts tested. Formally, we cannot exclude the accumulation of an inactive precursor, but preliminary Western blot experiments conducted with the pGIT008 amylase construct (amyL under the control of an $\mathrm{Lb}$. plantarum promoter) in strains NCIMB 8826, LbTGS1.4 and ATCC 393 did not show any accumulation of the precursor (data not shown). Similar observations have been made using the same amyL reporter in $E$. coli, where it was shown that a defect in the secretion machinery (limitation in signal peptidase I) did not result in the accumulation of the precursor, whereas another reporter protein $(\beta$ lactamase) accumulated to a large extent (van Dijl et al., 1988). One of the explanations suggested by the authors is an extremely tight coupling between the processing and the synthesis of $\alpha$-amylase (van Dijl et al., 1988). Alternatively, a proteolytic degradation of improperly folded precursors cannot be excluded.

We have retained the two most opposite strains (NCIMB 8826 and LbTGS1.4) for testing their capacity to secrete the model antigen M6-gp41E cloned in the expression vector pTG2281. Strain NCIMB 8826 was confirmed to be an efficient secretor; only the mature form of the antigen was present in the culture supernatant, and no precursor was detected intracellularly. The hypothesis that the low extracellular amylase activity in strain LbTGS1.4 would result from the poor secretion capacity of this strain was also clearly supported. A high intracellular retention (more that $90 \%$ ) of the M6gp41E precursor was observed in this case in LbTGS1.4 and the mature form of the protein could hardly be detected in the supernatant, where the precursor was also observed. The presence of the precursor in the culture supernatant is probably the result of cell lysis and we cannot exclude the possibility that the mature product observed in this case would result from nonspecific proteolytic cleavage. At this stage, we can only speculate on these observations. The strong secretion defect observed for LbTGS1.4 could be due to poor efficiency of the secretion machinery itself or to a limitation or a complete lack of specific chaperones, as already postulated for a number of heterologous proteins refractory to secretion in Gram-positive bacteria (Simonen \& Palva, 1993).

We constructed a second expression/secretion vector (pTG3237) with the objective of enhancing the level of expression of M6-gp41E by improving the TIR of the previous construction. Sequence analysis of TIR regions from a number of expression signals from $L b$. plantarum had previously revealed the occurrence of motifs complementary to the $5^{\prime}$-end of $16 \mathrm{~S}$ rRNA and the suggestion was made that these could strengthen translation initiation through mRNA-16S rRNA interactions (Hols et al., 1994). We therefore introduced a ' 5 '-box' upstream of the Shine-Dalgarno sequence and this indeed improved antigen production by a factor of 10 in Lb. plantarum. However, this modification could have indirect effects such as modifying the secondary structure of the TIR region or improving mRNA stability, which are known to contribute to translation efficiency (de Smit \& van Duin, 1990; Schauder \& McCarthy, 1989). A search for specific modifications of secondary structures in the TIR region revealed the presence of a hairpin with a $\Delta G=-4.6 \mathrm{kcal} \mathrm{mol}^{-1}(-19.32 \mathrm{~kJ}$ $\mathrm{mol}^{-1}$ ) (Tinoco et al., 1973) encompassing the ShineDalgarno sequence in pTG2281 while the same region in pTG3237 was devoid of any structure. A more systematic approach would of course be needed to show a 
direct correlation between the interaction with the $5^{\prime}$ end of the $16 \mathrm{~S}$ rRNA and/or the presence of secondary structures and the level of expression.

The transfer of this improved M6-gp41E expression vector in LbTGS1.4 did not result in stable expression of the antigen. We can speculate that increasing the expression level could result in toxic effects through complete saturation of the secretion machinery, which seems to be a limiting factor as the data with the pTG2281 expression vector already indicated. In NCIMB 8826, transfer of pTG3237 resulted in intracellular retention of the precursor at a low level and some of the mature form was also shown to remain associated with the cell pellet. Accumulation of the precursor is probably the consequence of an overloading of the secretion machinery resulting from the increase in expression level. Association of the mature form with the cell pellet has been observed in a number of cases dealing with heterologous secretion in Gram-positive bacteria (Simonen \& Palva, 1993). In LAB, the most illustrative example is the secretion of the tetanus toxin fragment C (TTFC) in Lc. lactis, where a large amount of the mature protein remains associated with the cell fraction (Wells et al., 1993b). Most authors suggest that the cell wall may act as a barrier to the diffusion of some proteins (Simonen \& Palva, 1993; Wells et al., 1993b; Saunders et al., 1987).

Production of $10 \mathrm{mg} \mathrm{M6-gp41E} \mathrm{(l} \mathrm{culture} \mathrm{medium)}{ }^{-1}$ is among the highest extracellular production levels for heterologous protein reported in LAB. To our knowledge, secretion in the milligram range was only published previously with a controlled expression system (based on the T7 promoter) in the case of TTFC ( $\left.3 \mathrm{mg} \mathrm{l}^{-1}\right)$ and murine interleukin $2\left(3 \mathrm{mg} \mathrm{l}^{-1}\right)$ in $L c$. lactis (Steidler et al., 1995; Wells et al., 1993b). The major difference observed in the capacity of $L b$. plantarum NCIMB 8826 and Lb. paracase $i$ LbTGS1.4 to secrete the M6-gp41E protein was recently confirmed with another antigen, the cholera toxin $B$ subunit ( $P$. Slos, unpublished results). These achievements open the way for further developments in the construction of $\mathrm{LAB}$ as live vectors for mucosal immunization.

\section{ACKNOWLEDGEMENTS}

We acknowledge B. M. Chassy and P. Conway for providing strains ATCC 393 and KLD, respectively. We thank H. Katinger for the generous gift of the anti-gp41E antibodies, and W. M. de Vos and G. Pozzi for providing plasmids pNZ10 11 and pGP603, respectively. We acknowledge $M$. Aguirre for her help in M6-gp41E purification and for stimulating discussions. This research was carried out in the framework of the Community Research Programme (contract no. BioT-CT94-3055). The authors acknowledge financial support of the French Agency for AIDS Research (ANRS).

\section{REFERENCES}

Bradford, M. M. (1976). A rapid and sensitive method for the quantitation of microgram quantities of proteins utilizing the principle of protein-dye binding. Anal Biochem 72, 248-254.
Casadaban, M. J. \& Cohen, S. (1980). Analysis of gene control signals by DNA fusion cloning in E. coli. J Mol Biol 138, 179-207.

Chassy, B. M. (1987). Prospects for the genetic manipulation of lactobacilli. FEMS Microbiol Rev 46, 297-312.

van Dijl, J. M., Smith, H., Bron, S. \& Venema, G. (1988). Synthesis and processing of Escherichia coli TEM $\beta$-lactamase and Bacillus licheniformis $\alpha$-amylase in E. coli: the role of signal peptidase I. Mol Gen Genet 214, 55-61.

Dutot, P. (1996). Evaluation des lactobacilles comme vecteurs vivants de vaccination. $\mathrm{PhD}$ thesis, Université Louis-Pasteur de Strasbourg.

Fernandes, C. F., Shahani, K. M. \& Amer, M. A. (1987). Therapeutic role of dietary lactobacilli and lactobacillic fermented dairy products. FEMS Microbiol Rev 46, 343-356.

Fischetti, V. A., Medaglini, D., Oggioni, M. \& Pozzi, G. (1993). Expression of foreign proteins on Gram-positive commensal bacteria for mucosal vaccine delivery. Curr Opin Biotechnol 4, 603-610.

Fitzsimons, A., Hols, P., Jore, J., Leer, R. J., O'Connell, M. \& Delcour, J. (1994). Development of an amylolytic Lactobacillus plantarum silage strain expressing the Lactobacillus amylovorus $\alpha$-amylase gene. Appl Environ Microbiol 60, 3529-3535.

Gibson, S. A. W. \& Conway, P. L. (1992). Recovery of a probiotic organism from human faeces after oral dosing. In Human Health: the Contribution of Microorganisms, pp. 119-141. Edited by S. A. W. Gibson. New York: Springer.

Hollingshead, S. K., Fischetti, V. A. \& Scott, J. R. (1986). Complete nucleotide sequence of type $6 \mathrm{M}$ protein of the group $\mathrm{A}$ Streptococcus: repetitive structure and membrane anchor. $J$ Biol Chem 261, 1677-1686.

Hols, P., Baulard, A., Garmyn, D., Delplace, B., Hogan, S. \& Delcour, J. (1992). Isolation and characterization of genetic expression and secretion signals from Enterococcus faecalis through the use of broad-host-range $\alpha$-amylase probe vectors. Gene 118, 21-30.

Hols, P., Ferain, T., Garmyn, D., Bernard, N. \& Delcour, J. (1994). Use of homologous expression-secretion signals and vector-free stable chromosomal integration in engineering of Lactobacillus plantarum for $\alpha$-amylase and levanase expression. Appl Environ Microbiol 60, 1401-1413.

Josson, K., Scheirlinck, T., Michiels, F., Plateeuw, C., Stanssens, P., Joos, H., Dhaese, P., Zabeau, M. \& Mahillon, J. (1989). Characterization of a Gram-positive broad-host-range plasmid isolated from Lactobacillus hilgardii. Plasmid 21, 9-20.

Klijn, N., Weerkamp, A. H. \& de Vos, W. M. (1995). Genetic marking of Lactococcus lactis shows its survival in the human gastrointestinal tract. Appl Environ Microbiol 61, 2771-2774.

Kok, J., van der Vossen, J. M. B. M. \& Venema, G. (1984). Construction of plasmid cloning vectors for lactic streptococci which also replicate in Bacillus subtilis and Escherichia coli. Appl Environ Microbiol 48, 726-731.

Laemmli, U. K. (1970). Cleavage of structural proteins during the assembly of the head of bacteriophage T4. Nature 27, 680-685.

Leclerc, C., Charbit, A., Martineau, P., Deriaud, E. \& Hofnung, M. (1991). The cellular location of foreign $B$ cell epitope expressed by recombinant bacteria determines its $\mathrm{T}$ cell-independent or $\mathrm{T}$ celldependent characteristics. J Immunol 147, 3545-3552.

Link-Amster, H., Rochat, F., Saudan, K. Y., Mignot, O. \& Aeschlimann, J. M. (1994). Modulation of a specific humoral immune response and changes in intestinal flora mediated through fermented milk intake. FEMS Immunol Med Microbiol 10, 55-64.

Marteau, P. \& Rambaud, J.-C. (1993). Potential of using lactic acid 
bacteria for therapy and immunomodulation in man. FEMS Microbiol Rev 12, 207-220.

Mercenier, A., Pouwels, P. H. \& Chassy, B. M. (1994). Genetic engineering of lactobacilli, leuconostocs and Streptococcus thermophilus. In Genetics and Biotechnology of Lactic Acid Bacteria, pp. 252-293. Edited by M. J. Gasson \& W. M. de Vos. Glasgow: Blackie Academic \& Professional.

Muster, T., Guinea, R., Trkola, A., Purtscher, M., Klima, A., Steindl, F., Palese, P. \& Katinger, H. (1994). Cross-neutralizing activity against divergent human immunodeficiency virus type 1 isolates induced by gp41 sequence ELDKWAS. J Virol 68, 4031-4034.

Nguyen, T. N., Hansson, M., Ståhl, S., Băchi, T., Robert, A., Domzig, W., Binz, H. \& Uhlén, M. (1993). Cell-surface display of heterologous epitopes on Staphylococcus xylosus as a potential delivery system for oral vaccination. Gene 128, 89-94.

Norton, P. M., Brown, H. W. G. \& Le Page, R. W. F. (1994). The immune response to Lactococcus lactis: implications for its use as vaccine delivery vehicle. FEMS Microbiol Lett 120, 249-256.

Oggioni, M. R., Manganelli, R., Contorni, M., Tommasino, M. \& Pozzi, G. (1995). Immunization of mice by oral colonization with live recombinant commensal streptococci. Vaccine 13, 775-779.

O'Sullivan, D. J. \& Klaenhammer, T. R. (1993). Rapid mini-prep isolation of high quality plasmid DNA from Lactococcus and Lactobacillus spp. Appl Environ Microbiol 59, 2730-2733.

Perdigon, G., de Macias, M. E. N., Alvarez, S., Oliver, G. \& de Ruiz Holgado, A. P. (1988). Systemic augmentation of the immune response in mice by feeding fermented milks with Lactobacillus casei and Lactobacillus acidophilus. Immunology 63, 17-23.

Perez-Martinez, G., Kok, J., Venema, G., van Dijl, J. M., Smith, H. \& Bron, S. (1992). Protein export elements from Lactococcus lactis. Mol Gen Genet 234, 401-411.

Posno, M., Leer, R. J., van Luik, K., van Giezen, N. M. J. F., Heuvelmans, B. C., Lokman, P. T. H. M. \& Pouwels, P. H. (1991). Incompatibility of Lactobacillus vectors with replicons derived from small cryptic Lactobacillus plasmids and segregational instability of the introduced vectors. Appl Environ Microbiol 57, 1822-1828.

Pouwels, P. H. \& Leer, R. J. (1993). Genetics of lactobacilli: plasmids and gene expression. Antonie Leeuwenhoek 64, 85-107.

Pouwels, P. H., Leer, R. J. \& Boersma, W. J. A. (1996). The potential of Lactobacillus as a carrier for oral immunization: development and preliminary characterization of vector systems for targeted delivery of antigens. J Biotechnol 44, 183-192.

Sambrook, J., Fritsch, E. F. \& Maniatis, T. (1989). Molecular Cloning: a Laboratory Manual, 2nd edn. Cold Spring Harbor, NY: Cold Spring Harbor Laboratory.

Samuelson, P., Hansson, M., Ahlborg, N., Andréoni, C., Götz, F., Bächi, T., Nguyen, T. N., Binz, H., Uhlén, M. \& Stăhl, S. (1995). Cell surface display of recombinant proteins on Staphylococcus carnosus. J Bacteriol 177, 1470-1476.

Saunders, C. W., Schmidt, B. J., Mallonee, R. L. \& Guyer, M. S. (1987). Secretion of human serum albumin from Bacillus subtilis. J Bacteriol 169, 2917-2925.

Schauder, B. \& McCarthy, J. E. G. (1989). The role of bases upstream of the Shine-Dalgarno region and in the coding sequence in the control of gene expression in Escherichia coli: translation and stability of mRNAs in vivo. Gene 78, 59-72.

Schneewind, O., Fowler, A. \& Faull, K. F. (1995). Structure of the cell wall anchor of surface protein in Staphylococcus aureus. Science 268, 103-106.

Schorr, J., Knapp, B., Hundt, E., Küpper, H. A. \& Amann, E. (1991). Surface expression of malarial antigens in Salmonella typhimurium: induction of serum antibody response upon oral vaccination of mice. Vaccine 9, 675-681.

Simonen, M. \& Palva, I. (1993). Protein secretion in Bacillus species. Microbiol Rev 57, 109-137.

Slos, P. (1990). Développement de systèmes de transfert de gènes et de vecteurs d'expression chez Streptococcus thermophilus. $\mathrm{PhD}$ thesis, Université Louis-Pasteur de Strasbourg.

Slos, P., Bourquin, J.-C., Lemoine, Y. \& Mercenier, A. (1991). Isolation and characterization of chromosomal promoters of Streptococcus salivarius subsp. thermophilus. Appl Environ Microbiol 57, 1333-1339.

de Smit, M. H. \& van Duin, J. (1990). Secondary structure of the ribosome binding site determines translation efficiency: a quantitative analysis. Proc Natl Acad Sci USA 87, 7668-7672.

Steidler, L., Wells, J. M., Raeymaekers, A., Vandekerckhove, J., Fiers, W. \& Remaut, E. (1995). Secretion of biologically active murine interleukin-2 by Lactococcus lactis subsp. lactis. Appl Environ Microbiol 61, 1627-1629.

Taguchi, H. \& Ohta, T. (1991). D-Lactate dehydrogenase is a member of the D-isomer-specific 2-hydroxyacid dehydrogenase family : cloning, sequencing and expression in Escherichia coli of the L-lactate dehydrogenase gene of Lactobacillus plantarum. $J$ Biol Chem 266, 12588-12594.

Tinoco, I., Jr, Borer, P. N., Dengler, B., Levine, M. D., Uhlenbeck, O. C., Crothers, D. M. \& Gralla, J. (1973). Improved estimation of secondary structure in ribonucleic acids. Nature New Biol 246, $40-41$.

Towbin, H., Staehelin, T. \& Gordon, J. (1979). Electrophoretic transfer of protein from polyacrylamide gels to nitrocellulose sheets: procedure and some applications. Proc Natl Acad Sci USA 76, 4350-4354.

Van Asseldonk, M. (1993). Production and secretion of heterologous proteins by Lactococcus lactis. $\mathrm{PhD}$ thesis, Agricultural University of Wageningen.

Van Asseldonk, M., de Vos, W. M. \& Simons, G. (1993). Functional analysis of the Lactococcus lactis usp45 secretion signal in the secretion of a homologous proteinase and a heterologous $\alpha-$ amylase. Mol Gen Genet 240, 428-434.

Wells, J. M., Wilson, P. W., Norton, P. M., Gasson, M. J. \& Le Page, R. W. F. (1993a). Lactococcus lactis: high-level expression of tetanus toxin fragment $\mathrm{C}$ and protection against lethal challenge. Mol Microbiol 8, 1155-1162.

Wells, J. M., Wilson, P. W., Norton, P. M. \& Le Page, R. W. F. (1993b). A model system for the investigation of heterologous protein secretion pathways in Lactococcus lactis. Appl Environ Microbiol 59, 3954-3959.

Received 7 January 1997; revised 8 April 1997; accepted 15 April 1997. 